\title{
Primate Ranching - Results of an Experiment
}

\author{
Russell A. Mittermeier, Robert C. Bailey, \\ Leslie E. Sponsel and Katherine E. Wolf
}

It is becoming increasingly difficult for biomedical research workers to get the wild primates they consider essential for their work. Successful primate ranching could help solve the problem. In 1967 a well-known animal dealer in Colombia, Mike Tsalickis of Leticia, released over $\mathbf{5 0 0 0}$ squirrel monkeys on an island in the Amazon in the hope of quick breeding results. Five years later he estimated the island monkey population at over $\mathbf{2 0 , 0 0 0}$, and the experiment appeared to have been very successful; later counts, however, suggested considerable errors in the figures and that the monkeys had in fact decreased catastrophically. The authors describe this and other experiments, some successful, but only as a result of expensive supplemental feeding.

Wild-caught primates are used in biomedical research throughout the world..$^{5,9,14,18,20}$ The effects on the wild populations of this trade for laboratory use are less serious than the effects of the pet trade, habitat destruction or hunting for food, ${ }^{1,9,18,22.23}$ but it has special effect near major export centres, such as Leticia in Colombia, ${ }^{3}$ and Iquitos in Peru.(pers. obs.). In recent years, several exporting countries - Peru, Brazil, Ecuador, Colombia, India - have become more conservation-minded and have cut down or banned all primate exports. Where are supplies to come from?

Suggestions for reducing the laboratory drain on natural populations and ensuring a future supply include: 1 . stricter control and limitation of primate use only to situations where other animals are not suitable; $;^{2,9,10} 2$. minimum wastage of specimens and maximum recycling of living primates and cadavers; ${ }^{15,16,17} 3$. laboratory breeding of all or most primates needed $; 9,10.16$ and 4. 'primate ranching' or large-scale breeding under controlled natural or semi-natural conditions. ${ }^{9.15}$ This article briefly describes and evaluates the Santa Sofia experiment, one of the first major attempts at 'primate ranching' under natural conditions, and discusses some of its implications.

\section{The Experiment}

Mike Tsalickis, an animal dealer in Leticia, Amazonas, Colombia, started the Santa Sofia experiment in 1967 using squirrel monkeys Scimiri sciureus, the New World monkey most used in research and probably the most abundant Amazonian primate. Between 1967 and 1970 he released 5690 squirrel monkeys ( 1200 males, 4490 females) on Isla Santa Sofia, a 400 -hectare island in the Amazon about $33 \mathrm{~km}$ upriver from Leticia, formed by fluvial deposition some 45 years ago and previously uninhabited by primates. The vegetation consists of large stands of Cecropia and a mixture of deciduous and non-deciduous trees. The introduced monkeys could only leave the island by swimming at least one kilometre in a strong current to the mainland - a most unlikely occurrence. Hunting and trapping were prohibited, and 
three families living on the island were hired to prevent poaching. A few of the monkeys were occasionally provisioned with fresh fruits and monkey chow, and banana and guava trees were planted to supplement natural foods.

In 1971, Tsalickis estimated an annual reproduction rate of 80-85 per cent, which, combined with an ideal assumption of no mortality, enabled him to calculate the population of the island as $20,698 . .^{21,12}$ The significance was obvious: if primates could be bred so easily, the problem of a future supply was solved. To evaluate the census figures and experiment, Barbara Harrisson organised a multi-disciplinary team of seven researchers to make a detailed census. From June to August 1972 they collected data on squirrel monkeys and spent more than 350 hours censusing the Santa Sofia population; their total was 850-966. ${ }^{219}$ Since then, Bailey's more detailed studies indicate that even these figures are too high and should be 550-715.

Two interpretations are possible. Either the published estimates are inaccurate, or they are accurate and the population dropped from 20,890 to under 1000 in 18 months. In either case, as 5690 animals were introduced, it is clear that very high mortality occurred. The Santa Sofia experiment was not monitored, so it is impossible to determine details of population dynamics and causes of mortality. Predation, disease, starvation, malnutrition, stress resulting from capture, subsequent holding and transport, and social factors are all possible causes. Large-scale poaching has also been mentioned ${ }^{12}$ but this is unlikely to have caused a decline of $4000+$ animals, especially with caretakers on the island.

The study results shattered the idea that 'primate ranching' could be easily accomplished by releasing animals on a tropical island and leaving them alone for a few years. It is just not that simple. Many factors have to be considered, including similarity of the new area to the natural habitat, food and spatial requirements of the species, provisioning to supplement quality and quantity of natural foods, the population structure of introduced vs. natural groups, the consequences of mixing individuals from different natural groups, health of the introduced animals, and climatic and microclimatic conditions.

Primate breeding under seminatural conditions, but on a smaller scale than at Santa Sofia, has already been successfully carried out at Monkey Jungle in Florida and Cayo Santiago, off the south-east coast of Puerto Rico. In Monkey Jungle several species have bred in two different habitats: a rain forest composed of several Florida tree species together with imported South American tropical forest vegetation, and a native Florida hammock. ${ }^{6}{ }^{7}$ In less than 14 years 37 monkeys introduced into the 1.6-hectare rain forest in August 1960 increased to $150+$, and a group of six crab-eating macaques introduced into the 6-hectare hammock in 1933 had by 1974 increased to $150+$. Red uakaris Cacajao calvus rubicundus, red howlers Alouatta seniculus and several other New World monkeys have also bred in the rain forest.

On Cayo Santiago, a 15-hectare island heavily grazed by goats which had never had a native primate population, C.R. Carpenter and co-workers released about 400 rhesus macaques Macaca mulatta and eight pig-tailed macaques $M$. nemestrina between December 2, 1938, and January 2, 1939. The objects were to test 'the feasibility and scientific desirability of establishing and maintaining breeding colonies ... in a tropical climate where foods were thought to be plentiful, cheap and nutritionally adequate', and to provide opportunities for developing primate husbandry techniques. ${ }^{4}$ 
By $1944-45$, the rhesus colony had increased to about 600 animals; $200-300$ were harvested and sold, and small numbers were also sold during World War II for biomedical and disease research. In the late 1940s and early 1950s management deteriorated, the regular supplemental foods were only occasionally provided, signs of starvation appeared, and by 1956 only 150 monkeys remained. In the mid 1950s adequate food supplies were resumed, and detailed behaviour and ecology studies started which are still going on. Between 1957 and 1967, 300 animals were removed, but by 1971 numbers had increased again to $685 .^{4}$

It must, however, be emphasised that both populations are heavily provisioned. Monkey Jungle animals are fed seven times a day, every day. Their diet includes bananas, apples, peanuts, grapes, oranges, fresh fruits in season, a vitamin-enriched mixture of bread soaked in milk and eggs, and a commercially-prepared monkey food. ${ }^{6}$ Cayo Santiago rhesus monkeys are supplied every second day with monkey chow shipped from the US (at an average cost of $6 \mathrm{c}$ per monkey per day), since local fruits and vegetables, though readily available, lack sufficient minerals and proteins $;{ }^{4}$ and supplemental food is of course not the only expense involved.

The population growth of the provisioned Japanese macaques $M$. fuscata on Mount Takasaki, part of their natural range, is also relevant. In October 1950 Itani's first count of the single group there showed 175 monkeys; in the spring of 1953, his estimate was 220 . Provisioning was started in November 1952 (and still continues), and a 0.55 -hectare feeding ground was set up in March 1953, in which year Mount Takasaki was declared a national park, with a protected area of 330 hectares. ${ }^{11}$ By December 1962, the population had increased to 775 and the original group had split into three; by 1972 there were 1400 monkeys. Itani estimated that between 1950 and 1972 some 2500 were born on Mount Takasaki, of which 1300 died, disappeared or were captured. This is far more than would have been born under entirely natura! conditions, but such a large population could not have survived without the extra food supplies. Until recently, the macaques were fed sweet potatoes, soy beans, wheat, ground nuts, tangerines, apples and other foods. Now park authorities feed only sweet potatoes, soy beans and wheat, and park visitors can buy groundnuts to feed to them. Daily supplies for the 1400 monkeys include 400 kilograms of sweet potatoes, 18 kilograms of soy beans and 100 kilograms of wheat. Park entrance fees help to pay for food, park personnel, facilities and park maintenance, and monkey damage to crops and buildings near the park. ${ }^{11}$

Clearly such operations are quite costly. Carpenter, for instance, pointed out $^{4}$ that breeding on Cayo Santiago was not economically competitive with trapping and shipping wild rhesus, even though the knowri life histories of bred animals can make them more valuable than wild-caught specimens, so it is unlikely that breeding projects would substantially reduce demand for cheap, wild-caught primates-especially when one compares the large numbers required in research with the small numbers produced by projects like Cayo Santiago. But as primate populations continue to decrease and exporting countries restrict or entirely eliminate primate exports, research laboratories may have no choice.

Relocation of primates has at times been suggested as a means of saving endangered species, for example the golden lion marmoset Leontopithecus 
rosalia. Where habitat destruction is inevitable, endangered animals could be removed to other climatically and otherwise suitable areas where they did not occur or occurred only in low densities. But Tsalickis' Santa Sofia experiment with a relatively hardy species like Saimiri sciureus shows that we must be extremely careful about primate relocation, especially if failure to adapt to a new habitat could mean extinction. Santa Sofia remains a highly significant ongoing experiment, but its initial failure and the many questions it poses point to the need for further research and more ranching experiments, closely and continuously monitored by primatologists and other biologists, before we can look to primate ranching as a major source of primates for research.

\section{Acknowledgments}

We would like to thank Barbara Harrisson, who supervised all stages of this project except for the actual field work. Special thanks also to Mike Tsalickis for permitting field work on Santa Sofia and for other very generous assistance. Robert W. Cooper, Jorge I. Hernandez-Camacho and Don Hunsaker 11 provided invaluable assistance and encouragement for the study. Field personnel, in addition to the authors, were Ralph S. Baker (Dept of Natural Resources, Cornell University, Ithaca, New York), Dorothy S. Brown (Dept of Psychology, Cornell University) and Patrick von Hildenbrand (Dept of Biology, Universidad de los Andes, Bogota, Colombia). R.A.M. was partly supported by a National Science Foundation Graduate Fellowship and by the Hooton Fund, Dept of Anthropology, Harvard University, L.E.S. by the National Institutes of Health and Cornell University; and R.C.B. by the Hunsaker Foundation and Merck Sharp and Dohme Research Laboratories.

Russell A. Mittermeier, Dept. of Anthropology and Museum of Comparative Zoology, Harvard University, Cambridge, Mass. 02138, USA.

Robert C. Bailey, Dept. of Anthropology, Harvard University, Cambridge, Mass. 02138, Leslie E. Sponsel, Dept. of Anthropology, Cornell University, Ithaca, New York 14850, Katherine E. Wolf, Dept. of Anthropology, Yale University, New Haven, Conn. 06520,

\section{References}

1. AVILA-PIRES, F.D. de, 1972. The survival of South American primates. Int. Zoo Yb. 12 $13-14$.

2. BAILEY, R.C. et al., 1974. Progress of a breeding project for non-human primates in Colombia. Nature 248 (5447) 453-455.

3. BALDWIN, J.D. and BALDWIN, J.I., 1971. Squirrel monkeys (Saimiri) in natural habitats in Panama, Colombia, Brazil and Peru. Primates 12 1: 45-61.

4. CARPENTER, C.R., 1972. Breeding colonies of macaques and gibbons on Santiago Island, Puerto Rico. In: Breeding Primates (W. I. B. Beveridge, ed.), Karger, Basel, pp. 76-87.

5. COIMBRA-FILHO, A.F., 1972. Conservation and use of South American primates in Brazil. Int. Zoo Yb. 12:14-15.

6. DuMOND, F., 1967. Semi-free-ranging colonies of monkeys at Goulds Monkey Jungle. Int Zoo Yb. 7: 202-207.

7. - 1968. The squirrel monkey in a seminatural environment. In: The Squirrel Monkey (L. A. Rosenblum and R. W. Cooper, eds.), Academic Press, N. Y., pp. 87-145.

8. GOODWIN, W.J., 1975. Primate resources - current status and future needs. In: Primate Utilization and Conservation (G. Bermant and D. G. Lindburg, eds.), New York, pp. 5-14.

9. HARRISSON, B., 1971. Conservation of nonhuman primates in 1970. Primates in Medicine 5, Karger, Basel, pp. 99.

10. INTERNATIONAL PRIMATOLOGICAL SOCIETY, 1972. Appeal for the conservation of nonhuman primates. 4th IPS Congr., Aug. 1972, Portland, Oregon.

11. ITANI, J., 1975. Twenty years with Mount Takasaki monkeys. In: Primate Utilization and Conservation (G. Bermant and D. G. Lindburg, eds.), Wiley, N. Y., pp. 101-125.

12. JERKINS, T., 1972. Free range breeding of squirrel monkeys on Santa Sofia Island, Colombia. In: Breeding Primates (W. I. B. Beveridge, ed.), Karger, Basel, p. 144. 
13. - 1974. Appendix to Evaluation of squirrel monkey (Saimiri sciureus) ranching on Santa Sofia Island, Amazonas, Colombia. Int. Zoo Yb. 14239.

14. KIRTON, K.T., 1975. Needs of the pharmaceutical industry for experimental primates. In: Primate Utilization and Conservation (G. Bermant and D. G. Lindburg, eds.), Wiley, N. Y. pp. 21-24.

15. LINDBURG, D.G. and BERMANT, G., 1975. Summary: primate conservation and utilization. In: Primate Utilization and Conservation (G. Bermant and D. G. Lindburg, eds.), Wiley, N. Y., pp. 169-181.

16. MITTERMEIER, R.A. and FLEAGLE, J.G., 1973. A primate distribution program to end wastage of sacrificed specimens. Lab. Prim. Newsl. 12 2: 1-3.

17. OTIS, L.S., 1972. Recycling primates. Lab. Prim. Newsl. 11 4: 4.

18. SOUTHWICK, C.H., SIDDIQI, M.R. and SIDDIQI, M.F., 1970. Primate populations and biomedical research. Science 170: 1051-1054.

19. SPONSEL, L.E.etal., 1974. Evaluation of squirrel monkey (Saimiri sciureus) ranching on Santa Sofia Island, Amazonas, Colombia. Int. Zoo Yb. 14: 233-240.

20. THORINGTON, R.W., Jr., 1972. The importance of nonhuman primates for man. III. Congreso Nacional de Biologia, Iquitos, Peru.

21. TSALICKIS, M., 1972. Trapping, husbandry and transport conditions of South American primates destined for research. Int. Zoo $Y$ b. 12: 23-26.

22. WARLAND, M.A.G., 1972. The status of Latin American primates. Int. Zoo Yb. 12: $16-18$.

23. WHITNEY, R.A., Jr. 1975. A domestic primate production feasibility study. In: Primate Utilization and Conservation (G. Bermant and D. G. Lindburg, eds.), Wiley, N. Y., pp. 163-167.

\section{Increase in the Tamaraw}

\section{W. Kuehn}

Although the tamaraw occurred on Luzon during the Pleistocene, ${ }^{1}$ in historic times this buffalo has been restricted to the Philippine island of Mindoro. There it established a reputation for aggressiveness that made it widely known in the Philippines, but it was not described for science until 1888. It has been estimated that 10,000 tamaraw Bubalus mindorensis occupied Mindoro island in $1900^{2}$ but by 1949 numbers had declined to 1000 animals, and in 1953 fewer than 250 remained. ${ }^{4}$ In 1969 Harrisson estimated that about 100 survived in three of their four known areas. Poaching was the main cause of the decline. Thanks to Harrisson's and General Lindbergh's efforts, 1969 also marked the start of the Philippine Government's tamaraw conservation effort, and wardens and guards were posted at the Mt Iglit Game Refuge and Bird Sanctuary in Occidental Mindoro. Between May 1972 and March 1974 I conducted a tamaraw study on 2000 hectares of the refuge where the major tamaraw population was to be found.

In the lower areas of Mt Iglit a mosaic of heavy cover and open grazing lands affords excellent tamaraw habitat. Cows are usually found in the preferred interspersion of forest, talahib Saccharum spontaneum grassland, and cogon Imperata cylindrica grassland, but mature bulls are intolerant of other bulls, so many adults and most juvenile bulls are forced to utilise ranges without forest cover. Large tracts of forest, offering little favoured forage, and large expanses of Themeda-Alloteropsis grassland, which are usually remote from dense cover, are little used. Mt Iglit was declared a wildlife refuge in 1961 but ranching had continued on the study area until 1969, and the tamaraw dwindled to about 20 animals. ${ }^{3}$ Once guards had been installed poaching by outsiders stopped. Members of the Batangan tribe continue a small amount of hunting with spear traps and fires but this appears to have 